\title{
BMJ Open Cohort profile: Mental Health Living Longer: a population-wide data linkage to understand and reduce premature mortality in mental health service users in New South Wales, Australia
}

Grant Sara (D) ,1,2 Myu Arumuganathan, ${ }^{1}$ Wendy Chen, ${ }^{1}$ Fred Wu, ${ }^{1}$ David Currow, ${ }^{3}$ Matthew Large, ${ }^{4}$ Cornelis Mulder, ${ }^{5,6}$ Parashar Pravin Ramanuj, ${ }^{7}$ Philip M Burgess ${ }^{8}$

To cite: Sara G,

Arumuganathan $\mathrm{M}$, Chen $\mathrm{W}$, et al. Cohort profile: Mental Health Living Longer: a population-wide data linkage to understand and reduce premature mortality in mental health service users in New South Wales, Australia. BMJ Open 2019;9:e033588. doi:10.1136/ bmjopen-2019-033588

- Prepublication history for this paper is available online. To view these files, please visit the journal online (http://dx.doi org/10.1136/bmjopen-2019033588).

Received 14 August 2019 Revised 07 October 2019 Accepted 14 October 2019
Check for updates

(C) Author(s) (or their employer(s)) 2019. Re-use permitted under CC BY-NC. No commercial re-use. See rights and permissions. Published by BMJ.

For numbered affiliations see end of article.

Correspondence to

Dr Grant Sara;

Grant.Sara@health.nsw.gov.au

\section{ABSTRACT}

Purpose Health systems must move from recognition to action if we are to address premature mortality in people with mental illness. Population data registers are an essential tool for planning and monitoring improvement efforts. The Mental Health Living Longer (MHLL) programme establishes a population-wide data linkage to support research translation and service reform in New South Wales (NSW), Australia.

Participants A total of 8.6 million people who have had contact with NSW public and private health services between July 2001 and June 2018 are currently included in the study. Data include more than 120 million linked records from NSW data collections covering public and private hospital care, emergency departments, ambulance, community mental health services, cancer notifications and care, and death registrations. Linkage is occurring with population-wide breast and cervical cancer screening programmes. Data will be updated 6 monthly. Findings to date The cohort includes 970145 people who have received mental healthcare: $79 \%$ have received community mental healthcare, $35 \%$ a general hospital admission with a primary mental health diagnosis and $25 \%$ have received specialist mental health inpatient care. The most frequent pattern of care is receipt of community mental healthcare only $(50 \%)$. The median age of the mental health cohort is 34 years, and three-quarters are younger than 53 years. Eleven per cent of the mental health cohort had died during the observation period. Their median age at death was 69 years, which was younger than the median age at death for people accessing other health services.

Future plans The MHLL programme will examine (i) all-cause mortality, (ii) suicide, (iii) cancer mortality and (iv) medical mortality. Within each theme, the programme will quantify the problem in mental health service users compared with the NSW population, describe the people most affected, describe the care received, identify predictors of premature mortality, and identify variation and opportunities for change.

\section{INTRODUCTION}

Health systems must move from recognition to action if we are to reduce premature

\section{Strengths and limitations of this study}

- A population-wide data linkage in an integrated health system caring for a population of more than 8 million people.

- The study is being undertaken by the state government department responsible for health system planning and management with an explicit focus on translation and targeted service improvement.

- Inclusion of data from population cancer screening programmes for breast and cervical cancer, and a population-wide cancer treatment registry with statutory reporting requirements.

- Lack of data on primary care and office-based private psychiatric care.

- No current data on some important clinical issues including medications and non-procedural interventions.

mortality in people living with mental illness. ${ }^{1}$ People with mental illness have a twofold to threefold increase in mortality, and 10-20year reductions in life expectancy. ${ }^{2-5}$ Premature mortality occurs across the diagnostic spectrum, affecting people with psychotic and substance use disorders ${ }^{5}{ }^{6}$ as well as mood, eating and personality disorders. ${ }^{45}$ Some studies find that this 'mortality gap' is increasing, because people living with mental illness have not shared broader improvements in life expectancy. ${ }^{3} 78$ The growing evidence on the scale of this problem has led to calls for urgent and global action. ${ }^{139}$ In Australia, governments and professional bodies have committed to understanding and reducing this premature mortality. ${ }^{10} 11$

The causes of premature mortality in people with mental illness are complex. Liu et a have proposed a multilevel framework which identifies interactions between social 
determinants, health system factors, and individual factors related both to health behaviours and specific disorders. Suicide is a major cause of premature death, and contributes a high proportion of years of life lost because of its impact on younger people. ${ }^{4}$ However, more than twothirds of premature deaths in people with mental illness are due to preventable medical illnesses. ${ }^{348}$ Rates of death are increased due to coronary heart disease,${ }^{6}{ }^{12}$ respiratory disease, ${ }^{6}$ substance use disorders ${ }^{56}$ and cancer. ${ }^{13-15}$ Cancer case fatality rates are increased due to lifestyle factors (most notably smoking), lower participation in screening, later presentation for care, more frequent metastatic disease at first presentation, and less assertive and specialised cancer care. ${ }^{1316-19}$ The burden of preventable illness is also reflected in increased rates of hospitalisation for a wide range of ambulatory care sensitive conditions. ${ }^{2021}$

Population-wide data registries and collections have been an essential tool for identifying premature mortality, and will be equally important in efforts to understand and reduce it. Here, we describe the establishment of a linked data set for the population of New South Wales (NSW), Australia, which will be used to understand the factors contributing to premature mortality, to identify the groups and regions most at risk, to guide action and to monitor change. It includes data for people accessing specialist community and hospital mental health services in NSW, as well as comparable data for the whole NSW population, allowing detailed modelling of differences in care and outcomes between mental health service users and others.

\section{COHORT DESCRIPTION}

\section{Setting}

NSW is Australia's most populous state, with an estimated resident population of 8.1 million people in $2019^{22}$ and a net annual population growth of approximately $1.2 \%$. At approximately 800000 square kilometres, NSW has a slightly larger land area than France or the US state of Texas; however, $94 \%$ of the population lives in major cities or inner regional areas. More than one-third (35\%) of the NSW population was born in a country other than Australia, and more than half have $(54 \%)$ at least one parent born overseas. ${ }^{23}$ On average, each year over the last decade, $1.2 \%$ of the NSW population emigrated to other countries and $1.5 \%$ emigrated to other states. ${ }^{24}$

Australian health services are primarily governmentfunded. Within a federated system of government, responsibilities for mental healthcare are shared between Commonwealth (national) and state or territory governments. Approximately $65 \%$ of mental health service expenditure occurs by state or territory governments, which are responsible for acute and emergency hospital care, acute community care and long-term community mental healthcare for people with severe or enduring illness. ${ }^{25}$ These are typically provided through geographically organised local health districts. Commonwealth government subsidies for pharmaceuticals and private office-based primary and specialist care comprise around $30 \%$ of mental healthcare expenditure. Both layers of government purchase support services and some clinical services from non-government organisations. The balance of expenditure is from insurance and out-ofpocket costs, and includes a private hospital sector which primarily provides planned and voluntary inpatient care. The Mental Health Living Longer (MHLL) data set includes data from all state-operated health services and some private sector services.

\section{Governance}

The MHLL programme is being conducted by the NSW Ministry of Health, which is the department of state government responsible for the planning, funding, management and oversight of public hospital and community health services.

\section{Patient and public involvement}

The project has been established in response to the priorities of Australia's Fifth National Mental Health and Suicide Prevention Plan. A focus on improving physical health outcomes and reducing premature mortality has been identified as a priority by Australia's peak state and national mental health service user-representative bodies.

A project governance committee has been established with representation from NSW peak bodies representing general health consumers, mental health consumers and mental health carers, as well as an Aboriginal community representative. The project governance committee will set priorities for analysis and oversee the interpretation and dissemination of findings.

\section{Data linkage}

Data linkage is undertaken by the NSW Centre for Health Record Linkage $(\mathrm{CHeReL}),{ }^{26}$ which carries out probabilistic linkage of health-related data in accordance with NSW ethical, legal, privacy and confidentiality requirements. CHeReL conducts probabilistic record linkage via the ChoiceMaker software. ${ }^{27}$ This uses an automated blocking algorithm and machine learning techniques to assign matching weights to records, creating a statewide NSW Master Linkage Key for included collections. Variables used in linkage include first, middle and last names, gender, date of birth, address (included as a time-dependent variable) and health service person identifiers (medical record numbers). An encrypted but unique project-specific Project Person Number is then created for each person identified in the linkage. The linkage process is designed to achieve a false positive rate of around 5 per 1000 records, and is subject to regular quality assurance. $^{28}$

\section{Data sets included}

Overview

The MHLL programme has approval for ongoing linkage of NSW health data collections covering public and private hospital care, emergency departments (EDs), 


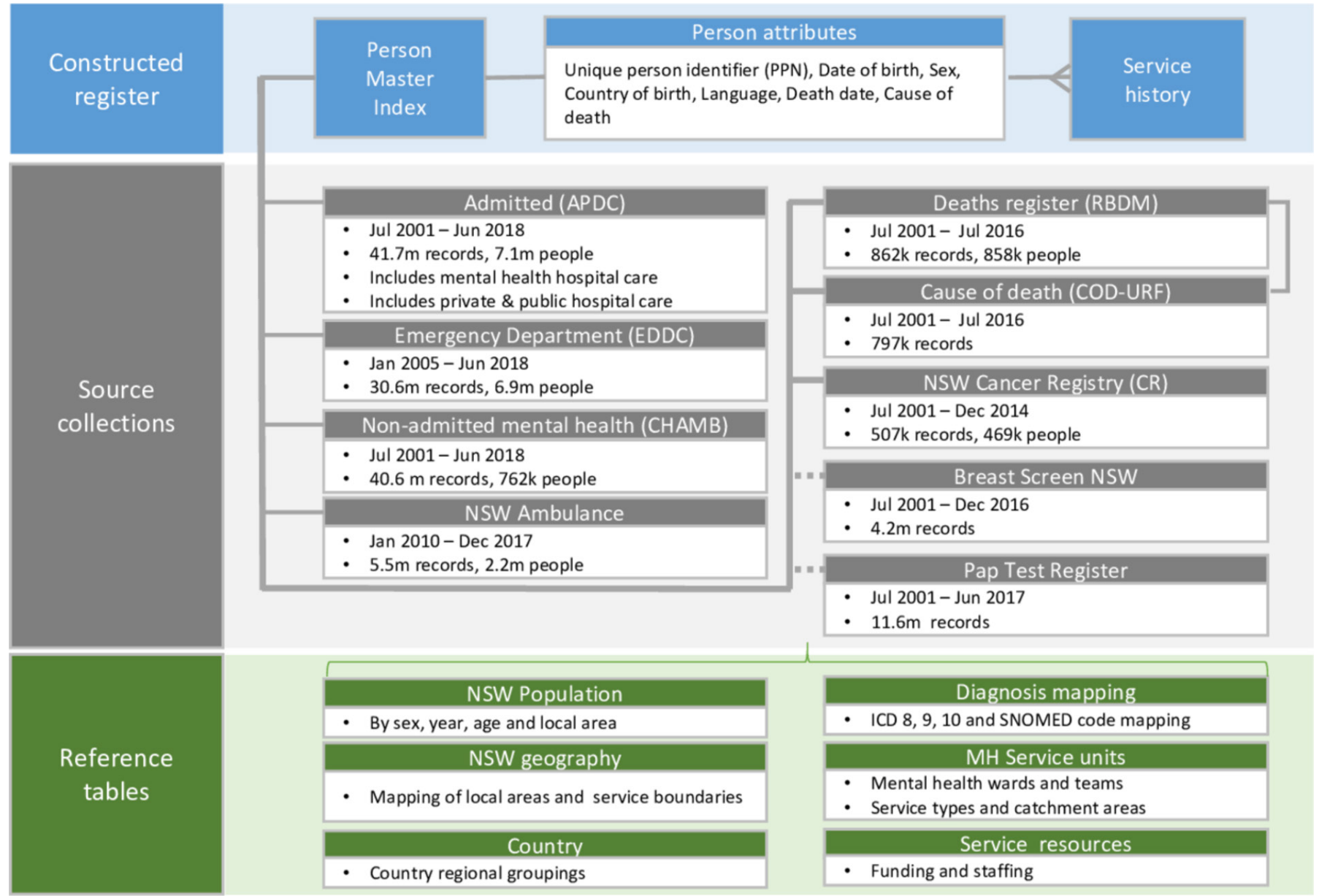

Figure 1 Data structure, Mental Health Living Longer data set. Numbers of records and individuals at initial linkage. APDC, Admitted Patient Data Collection; CHAMB, Community Health and Ambulatory Mental Health data collection. COD-URF, Cause of Death Unit Record File; Dec, December; EDDC, Emergency Department Data Collection; ICD, International Classification of Diseases; Jan, January; Jul, July; Jun, June; k, thousand; m, million; MH, mental health; NSW, New South Wales; PPN, Project Person Number; RBDM, Registry of Births Deaths and Marriages; SNOMED, Systematised Nomenclature of Medicine.

ambulance, community mental health services, and cancer screening and care. These collections are linked to population registrations of the fact and cause of death. Data dictionaries for all collections are available online. ${ }^{29}$ Currently, the linkage has been approved but not yet completed for two population cancer screening registers (breast and cervical cancers). Data updates will occur 6 monthly for most collections.

The linked data sets have been used to construct a single Person Master Index, which summarises contacts for all people in NSW who have had contact with any in-scope service (figure 1). Summary person characteristics, including date of birth, sex, country of birth and preferred language, are derived from the first valid record in all collections. More volatile variables, such as diagnosis, region of residence or pattern of service contact, will be derived as required for specific analyses and observation periods. Reference data on NSW population, mortality and geography will be drawn from the Australian Bureau of Statistics data sets and projections. Reference and mapping tables have been constructed for
NSW Health service structures, regions, resources and diagnostic systems.

The collection currently includes approximately 120 million records for 8.6 million individuals: we estimate that this represents approximately $70 \%$ of people residing in NSW from 2001 to 2018. No data are available on people who have had no contact with any in-scope service, such as people with no health service contact, or those whose only health service contact has been with nationally funded primary care or private outpatient services.

\section{NSW Admitted Patient Data Collection}

The collection includes all separations from NSW public hospitals, private hospitals and day procedure centres. It includes information on demographics, episode of care details, primary and additional diagnoses, and procedures. The data set includes a primary diagnosis and up to 50 supplementary diagnoses which have been extracted from clinical records by trained coders and recorded using the Australian modification of the Internatinoal 
Classification of Diseases, Tenth Edition (ICD10-AM).$^{30}$ Limitations of the data set include: absence of data on interventions other than coded procedures; absence of data on medication, physical investigations or observations; and varying quality of data on marital status, employment and accommodation type. Data are currently included from July 2001 to June 2018 and will be updated 6 monthly.

\section{NSW Emergency Department Data Collection}

The collection includes details of presentations for all reasons to EDs of NSW public hospitals. It includes data on: demographics; mode of presentation; timing of triage, assessment and departure; urgency category at triage; and disposition outcome. The reason for ED care is recorded as a single final diagnosis by ED clinicians, along with a freetext field identifying the presenting problem as recorded by triage clinicians. Diagnostic recording has transitioned from ICD-9 and ICD-10 to Systematised Nomenclature of Medicine, Clinical terms (SNOMED-CT) nomenclature. ${ }^{31}$ For all analyses, SNOMED and ICD-9 diagnoses are first mapped to ICD-10 diagnoses for analysis, using NSW Health reference tables (available from the authors on request). The primary limitation of the ED data set is the limited depth of diagnostic coding. The project will examine the use of text fields recorded at triage to improve diagnostic sensitivity. Some very small rural hospitals do not contribute data to this collection. Data are currently included from January 2005 to June 2018 and will be updated 6 monthly.

\section{NSW Ambulance Data Collection}

The collection includes data on all NSW ambulance callouts, with records from computer-aided dispatch systems, the patient healthcare record and (since 2011) the NSW ambulance electronic medical record. It includes demographic details, reasons for callout, and clinical and transport details. Clinical conditions are recorded using a custom code-set of condition and problem types, and via extensive free text. Specific flags exist for the presence of a mental health assessment and the application of mental health-specific emergency care protocols. Limitations of the collection include: significant changes in variables and collection methods during the period of interest; inconsistent completion of mandatory flags and fields; and a later start date than other collections. Data are currently included from January 2010 to December 2017 and will be updated annually. Nearly all NSW ambulance callouts are followed by transport to hospital, and ambulance data will be linked to corresponding ED or hospital episodes of care to provide additional information on reasons for presentation and pathways to care. For this reason, the study has not requested ambulance variables relating to the individual's address or area of residence; however, these variables were used in the data linkage.
NSW Mental Health Ambulatory Data Collection

The collection includes data from all non-admitted public mental healthcare, including community mental health services, acute and emergency teams, day programmes, outpatients, outreach services and hospital consultationliaison services. Data items include demographics, legal status, individual contact details, service or care type, and the number and professional grouping of clinicians. A primary diagnosis and up to three additional diagnoses are recorded by clinicians using ICD-10-AM. Limitations of the data set include: inconsistent completeness and depth of diagnostic coding, with high rates of missing or non-specific diagnoses, particularly for people with short episodes of community care; absence of data on medication, psychological interventions or observations; and incomplete recording of contacts in the earlier years of collection. Data are currently included from January 2000 to June 2018 and will be updated 6 monthly.

\section{NSW Registry of Births, Deaths and Marriages}

The collection records all births and deaths in NSW and includes the date, time and location of death. Limitations of the data set include inconsistent accuracy of the coding of the location of death, and that only deaths occurring within NSW are recorded. Data are currently included from July 2001 to June 2018 and will be updated 6 monthly.

\section{Australian Bureau of Statistics Cause of Death Unit Record File}

The collection includes details on the cause of death for all deaths in NSW. It includes a primary and additional contributory cause of death codes in ICD-10 format, as specified by the death certificate or coroner. The primary limitation of the data set is that delays in the finalisation of coronial data create a substantial time-lag before data are available. Coding by clinicians and coroners may also underestimate the number of suicide deaths. Data are currently included from July 2001 to December 2015 and will be updated 6 monthly.

\section{NSW Cancer Registry}

Notification of cancer diagnoses is mandatory under the NSW Public Health Act. The cancer registry includes details of notifications from pathology laboratories, hospitals, radiotherapy units and oncology departments. It includes data on demographics, cancer type, staging, morphology, year of diagnosis and cancer-related reasons for death. The registry also currently includes data on chemotherapy and radiotherapy treatments, but this was not available for much of the period currently covered by the study. Data are currently included from July 2001 to December 2014 and will be updated annually.

\section{BreastScreen NSW}

The collection records data from a population-wide screening mammography programme. The programme is offered to all female NSW residents aged 50-74 years via biannual letter. Uptake rates have increased steadily over the past 5 years with a $52.7 \%$ participation rate of 
the NSW target population in the 2015-2016 period. ${ }^{32}$ The collection includes data on demographics, screening activity, the number and type of assessments, lesions discovered, histopathology, primary treatment offered and death. Limits of the data collection include: incomplete uptake of screening; limitations (false positives and negatives) of screening mammography; and limited and summarised data on treatment. Inclusion of the data has been approved and the initial linkage is planned to occur by September 2019 .

\section{NSW Pap Test Register}

Regular screening for cervical cancer is offered to all NSW women aged 25-74 years, via Pap smear or cervical (human papillomavirus (HPV)) testing. The cervical screening test replaced the Pap smear from December 2017 and screens for HPV in cervical cell samples. Uptake rate of cervical cancer screening in NSW was $56.3 \%$ of the target population in 2015-2016. ${ }^{33}$ Around $0.8 \%$ of participants opt to not have their data recorded and available for linkage. ${ }^{34}$ The collection includes data on demographics, test details, test results, cytology, histology (biopsy results and results of hysterectomies) and HPV test results. Inclusion of the data has been approved and the initial linkage is planned to occur by September 2019.

\section{Characteristics of the cohort}

The linked data set currently includes records for 8.6 million individuals. Using reference data on population, births, interstate arrivals and overseas arrivals, ${ }^{24} 35$ we estimate that there were 12.2 million unique individuals resident in NSW between 2001 and 2018. Therefore, the study data set represents the approximately $70 \%$ of individuals in the NSW population who had at least one contact with an ED, public or private hospital, ambulance, cancer care or mental health service in that period. People with no health service contact, or whose only health contact was with a private outpatient health service, including primary care or office-based specialist services funded by Australia's national government, are not included in the data set. The planned studies will examine care and outcomes in people receiving mental healthcare, comparing these to the whole NSW population or appropriately matched control groups.

\section{Mental health cohort}

The mental health cohort has been designed to comprise three overlapping groups of service users, reflecting different patterns of care within the health system (see figure 2). These are: (i) hospital care in a specialist mental health unit; (ii) hospital care for a primary diagnosis of a mental health condition outside a specialist mental health unit or (iii) community care by a specialist mental health community team. Table 1 summarises the characteristics of these groups. Sex and country of birth data are drawn from Person Master Index. Age profile is derived from the date of birth to the first valid service contact date for each person to reflect age at first contact. Data

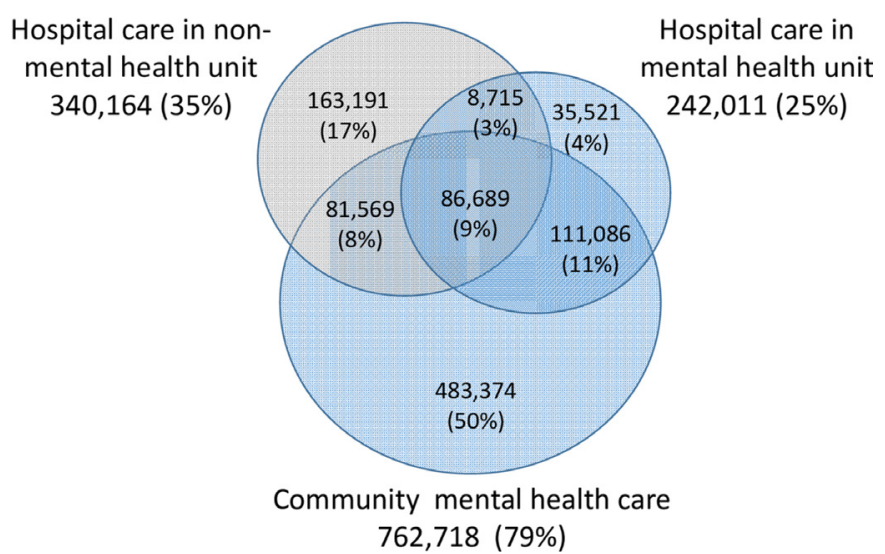

Figure 2 Mental health cohort, comprising 970145 people with at least one (i) hospital admission to a specialised mental health unit, (ii) hospital admission with a primary diagnosis of a mental health condition to a non-mental health unit or (iii) contact with a specialist community mental health team. Percentages rounded to the nearest whole per cent, numbers may not appear to add due to rounding.

on address of residence and diagnoses are drawn from the last valid record per person. The cohort currently comprises 970145 individuals who have received at least one of these three types of mental healthcare. More than $760000(79 \%)$ have received community mental healthcare, $35 \%$ had a general hospital admission with a primary mental health diagnosis and $25 \%$ have had at least one admission to a mental health unit. The most frequent pattern of care was receipt of community mental healthcare only $(50 \%)$. The majority $(81 \%)$ of people who received specialist hospital care also had contact with community mental health teams. More than one-sixth of the cohort $(17 \%)$ had a hospital admission for a primary mental health diagnosis but had no other contact with specialist hospital care or community mental health teams.

The overall mental health cohort included slightly more females $(51.2 \%)$ than males. The median age of the mental health cohort was 34 years: three-quarters were younger than 53 years, reflecting the onset of many mental health conditions in adolescence and young adulthood. One-fifth were born outside Australia and two-thirds $(66 \%)$ lived in major cities.

The three overlapping subgroups of people receiving mental healthcare differed in several important characteristics. People receiving community mental healthcare had a younger median age (32 years) than people admitted for hospital care, while more than one-quarter (28\%) of people admitted to non-specialist mental health units were aged 65 years or over. Proportionally, more people receiving hospital care lived in areas in the most disadvantaged two quintiles, while people receiving community care were skewed towards more advantaged areas. Community mental health data had a high rate of missing or unspecified diagnoses: $44 \%$ of individuals in that data set did not have a specific diagnosis recorded. Many of these were individuals with very brief community 
Table 1 Characteristics of the mental health service user cohort. Service use defined by (i) hospital admission to a specialised mental health unit, (ii) hospital admission with a primary diagnosis of a mental health condition to a non-mental health unit or (iii) contact with a specialist community mental health team. Groups are not mutually exclusive. 'Any mental healthcare' group are people with at least one contact in one of the three groups

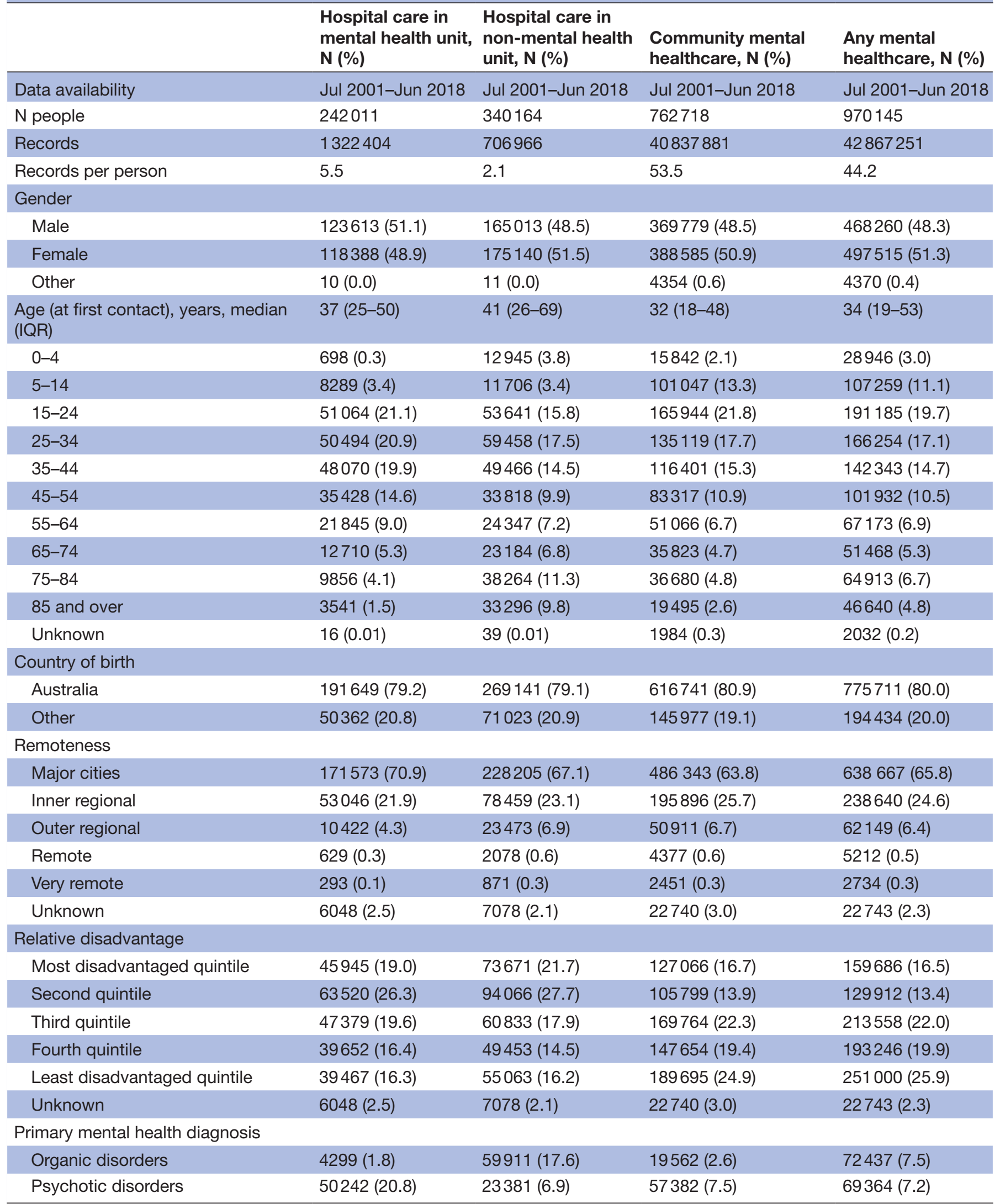




\begin{tabular}{|c|c|c|c|c|}
\hline & $\begin{array}{l}\text { Hospital care in } \\
\text { mental health unit, } \\
\text { N (\%) }\end{array}$ & $\begin{array}{l}\text { Hospital care in } \\
\text { non-mental health } \\
\text { unit, } \mathbf{N}(\%)\end{array}$ & $\begin{array}{l}\text { Community mental } \\
\text { healthcare, } \mathrm{N}(\%)\end{array}$ & $\begin{array}{l}\text { Any mental } \\
\text { healthcare, } \mathrm{N}(\%)\end{array}$ \\
\hline Affective disorders & $67166(27.8)$ & $41017(12.1)$ & $122067(16.0)$ & $153683(15.8)$ \\
\hline Anxiety disorders & $10359(4.3)$ & $30387(8.9)$ & $39924(5.2)$ & $63822(6.6)$ \\
\hline Post-traumatic and stress disorders & $34834(14.4)$ & $26890(7.9)$ & $45242(5.9)$ & $77588(8.0)$ \\
\hline Personality disorders & $8972(3.7)$ & $3890(1.1)$ & $14480(1.9)$ & $17058(1.8)$ \\
\hline Intellectual disability & $396(0.2)$ & $3154(0.9)$ & $1648(0.2)$ & $4509(0.5)$ \\
\hline Other mental health disorders & $15028(6.2)$ & $49901(14.7)$ & 85609 (11.2) & $126239(13.0)$ \\
\hline Deaths (at June 2018) & $28142(11.6)$ & $84571(24.9)$ & $82017(10.8)$ & $142988(14.7)$ \\
\hline Median age at death (IQR), years & $66(52-83)$ & $82(69-89)$ & $77(60-86)$ & $81(66-88)$ \\
\hline
\end{tabular}

Jul, July; Jun, June.

contacts. Because this group was the largest component of the overall mental health cohort, one-quarter $(26 \%)$ of the overall mental health cohort did not have a specific mental health diagnosis recorded. The diagnostic profile of the two hospital-based groups differed substantially: nearly half of the people admitted to specialist mental health units had diagnoses of psychotic or affective disorders, while nearly half of the people admitted to non-specialist units had primary diagnoses of organic mental disorders (including dementia) or substance use disorders.

\section{NSW population health service data}

Comparison data for the mental healthcare cohort will be drawn from health service use data for the whole NSW population (table 2). People admitted to hospital care exclude people admitted to a mental health unit or with a primary mental health diagnosis, who are included in the mental health cohort. The hospital group was younger, with a median age of 33 years and more than one-fifth $(22 \%)$ being aged under 5 years. Fifty-four per cent were female. People presenting to NSW EDs had a similar profile to those admitted to hospital, with a median age of 32 years and around one-sixth (17\%) being aged under 5 years. Cancer registration data included the oldest cohort (median age 67 years) and had a different social gradient to most other collections, with a higher proportion of notifications being in people who lived in more advantaged regions.

\section{Deaths}

Tables 1 and 2 presents the number of deaths and median age at death for each subgroup. These crude mortality figures do not adjust for varying periods of observation, or for different age and sex distributions among these populations. Component studies of the MHLL programme will examine adjusted and standardised mortality rates for mental health service users and matched comparison groups. Crude mortality rates ranged from $11 \%$ (hospital care group) to $50 \%$ (cancer registrations). In the mental health cohort, around $11 \%$ of people receiving community and/or specialist mental health inpatient care had a death record within the study period, as did $25 \%$ of people with non-specialist mental health admission.

The youngest median age at death (69 years) was seen in people receiving mental healthcare, particularly those admitted to a specialist mental health unit. By contrast, the median age at death for all people admitted to NSW hospitals was 81 years and the median age at death for cancer registrations was 77 years. MHLL studies will examine life expectancy and years of life lost in mental health service users compared with appropriate comparison groups.

\section{FINDINGS TO DATE}

The MHLL programme's research questions are organised into four broad themes: (i) all-cause mortality; (ii) suicide; (iii) cancer mortality and (iv) medical mortality (figure 3). Each theme has a planned sequence of data development and analysis. First, we will quantify the problem, then describe the people affected and the care received, identify predictors of premature mortality and, finally, identify variation and opportunities for change. Work has commenced on each of these themes, with the initial focus being to develop the structures and methods which will support ongoing updating of the data set. A method for 
Table 2 Comparison data for NSW population. People with at least one contact for each service types. Groups are not mutually exclusive

\begin{tabular}{|c|c|c|c|c|}
\hline & Hospital care, N (\%) & $\begin{array}{l}\text { Emergency } \\
\text { department, N (\%) }\end{array}$ & Ambulance, N (\%) & $\begin{array}{l}\text { Central cancer } \\
\text { register, } \mathbf{N}(\%)\end{array}$ \\
\hline Records availability & Jul 2001-Jun 2018 & Jan 2005-Jun 2018 & Jan 2010-Dec 2017 & Jul 2001-Dec 2014 \\
\hline People & 7157453 & 6973640 & 2045165 & 469359 \\
\hline Records & 41764748 & 30551362 & 5525619 & 507065 \\
\hline Records per person & 5.8 & 4.4 & 2.7 & 1.1 \\
\hline \multicolumn{5}{|l|}{ Gender } \\
\hline Male & $3264473(45.6)$ & 3551485 (49.1) & $1023386(50.0)$ & 259255 (55.2) \\
\hline Female & $3892782(54.4)$ & 3421898 (50.9) & $1021771(50.0)$ & 210104 (44.8) \\
\hline Other & $198(0.0)$ & $257(0.0)$ & $8(0.0)$ & \\
\hline $\begin{array}{l}\text { Age (derived from first contact/ } \\
\text { service record), years, median } \\
\text { (IQR) }\end{array}$ & $33(11-55)$ & $32(13-54)$ & $51(26-73)$ & $67(57-77)$ \\
\hline $0-4$ & $1606217(22.4)$ & $1148196(16.5)$ & $115634(5.7)$ & $1326(0.3)$ \\
\hline $5-14$ & $328904(4.6)$ & 694043 (10.9) & $126667(6.2)$ & $1395(0.3)$ \\
\hline $15-24$ & 780269 (10.9) & 938209 (13.5) & $238592(11.7)$ & $3934(0.8)$ \\
\hline $25-34$ & $1032298(14.4)$ & $950438(13.6)$ & $207031(10.1)$ & $10528(2.2)$ \\
\hline $35-44$ & 800469 (11.2) & $790021(11.3)$ & $205130(10.0)$ & $25035(5.3)$ \\
\hline $45-54$ & 779116 (10.9) & $717820(10.3)$ & $212832(10.4)$ & $57181(12.2)$ \\
\hline $55-64$ & $724592(10.1)$ & $646657(9.3)$ & $224358(11.0)$ & 104681 (22.3) \\
\hline $65-74$ & $568980(8.0)$ & $508794(7.3)$ & 250750 (12.3) & $123285(26.3)$ \\
\hline $75-84$ & $397863(5.6)$ & $399279(5.7)$ & $266580(13.0)$ & $102015(21.7)$ \\
\hline 85 and over & $138450(1.9)$ & $179112(2.6)$ & $197562(9.7)$ & $39977(8.5)$ \\
\hline Unknown & $295(0.0)$ & $1071(0.0)$ & $29(0.0)$ & $2(0.0)$ \\
\hline \multicolumn{5}{|l|}{ Country of birth } \\
\hline Australia & 5483795 (76.6) & $5165063(74.1)$ & $1517467(74.2)$ & 329831 (70.3) \\
\hline Other/Unknown & $1673658(23.4)$ & $1808577(25.9)$ & $527698(25.8)$ & $139528(29.7)$ \\
\hline \multicolumn{5}{|l|}{ Remoteness } \\
\hline Major cities & $5165390(72.2)$ & $4925634(70.6)$ & - & $322443(68.7)$ \\
\hline Inner regional & $1518899(21.1)$ & $1584361(22.7)$ & - & $115108(24.5)$ \\
\hline Outer regional & $383112(5.4)$ & $377232(5.4)$ & - & $29653(6.3)$ \\
\hline Remote & $25490(0.4)$ & $21873(0.3)$ & - & $1601(0.3)$ \\
\hline Very remote & $8635(0.1)$ & $7570(0.1)$ & - & $503(0.1)$ \\
\hline Unknown & $55927(0.8)$ & $56970(0.8)$ & - & $51(0.0)$ \\
\hline \multicolumn{5}{|l|}{ Relative disadvantage } \\
\hline Most disadvantaged quintile & $1466690(20.5)$ & $1406193(20.2)$ & - & $69326(14.8)$ \\
\hline Second quintile & $1886785(26.4)$ & $1905532(27.3)$ & - & $59764(12.7)$ \\
\hline Third quintile & $1336014(18.7)$ & $1322896(19.0)$ & - & $107520(22.9)$ \\
\hline Fourth quintile & $1097841(15.3)$ & $1084484(15.6)$ & - & $100330(21.4)$ \\
\hline Least disadvantaged quintile & $1314196(18.4)$ & $1197565(17.2)$ & - & $132368(28.2)$ \\
\hline Unknown & $55927(0.8)$ & $56970(0.8)$ & - & $51(0.0)$ \\
\hline Deaths at June 2018 & $769529(10.8)$ & $586039(8.4)$ & $349311(17.1)$ & $233022(49.6)$ \\
\hline Median age at death (IQR), years & $81(71-88)$ & $82(70-89)$ & $83(72-89)$ & $77(67-85)$ \\
\hline
\end{tabular}

Dec, December; Jan, January; Jul, July; Jun, June; NSW, New South Wales. 


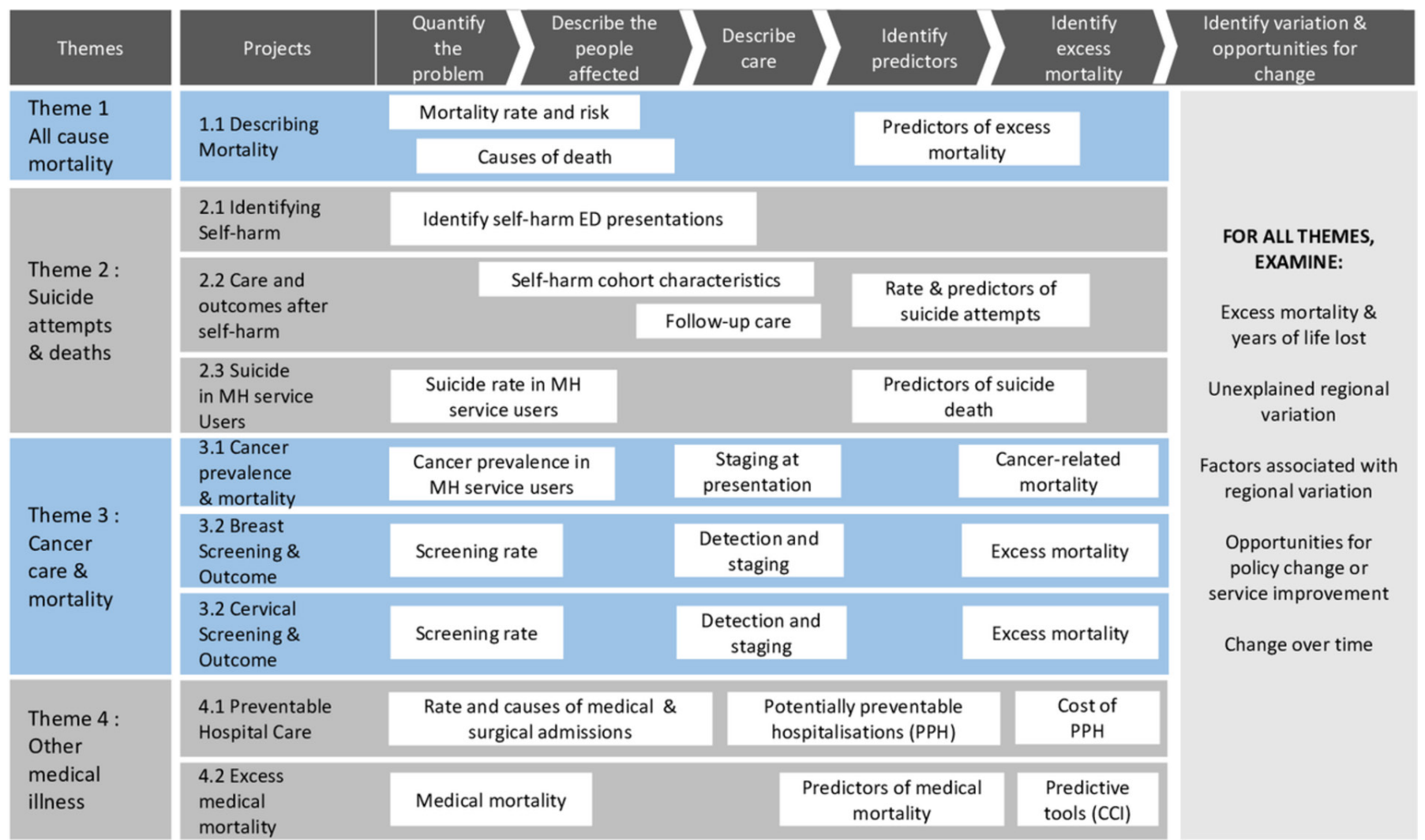

Figure 3 Overview of research questions and planned sequence of analyses, Mental Health Living Longer project. CCI, Charlson Comorbidity Index; ED, emergency department; $\mathrm{MH}$, mental health; $\mathrm{PPH}$, potentially preventable hospitalisations.

using free-text data to identify ED self-harm presentations has been piloted, ${ }^{36}$ and appears to substantially increase the sensitivity and specificity of detection. The method is currently being refined.

\section{STRENGTHS AND LIMITATIONS OF THE STUDY}

The strength of the programme is its population-wide reach and large scale. Data are available for a populationwide hospital and community health system for a population of more than 8 million persons. This allows identification of a wider spectrum of people with mental health issues, including users of specialised mental health services as well as people with diagnoses of mental health and substance problems who are not in touch with specialist mental health services. The study includes both public and private hospital data, providing a complete picture of all hospital care within NSW in the period. The study also includes cancer incidence/staging information from a population-wide register with mandatory notification, and will include data from population-wide cancer screening programmes for breast and cervical cancer.

The study data set also has a number of limitations. First, the study currently lacks any data from primary care and private office-based specialist mental or physical healthcare services funded by Australia's national ('Commonwealth') government. Integration between state-funded specialist mental health services and nationally funded primary care services is a critical issue for physical healthcare of mental health service users. Australia has several national minimum data sets which could potentially be linked to the project's data to examine these issues. These have not been included in the first stage of the project because they require separate planning and approval processes; however, this linkage will be considered in the future development of the MHLL programme. The lack of available primary care data also means that the collections focus on people with more severe illness who are in contact with specialist and emergency services. Improving care for these people is the primary aim of the study; therefore study findings may not generalise to people with less severe conditions treated only in primary care.

Second, the data collections currently available to the study have limited information on many important clinical issues. In particular, the study currently has little or no information on medication, non-procedural interventions, investigations and physical observations. The collections vary systematically in their quality and depth of diagnostic coding. Medication data are not currently available in Australia's routine state or national data collections. Some medication data may become available during the study, both for hospital-based care through the rollout of electronic prescribing systems in NSW hospitals, and for outpatient care through possible future linkage to Australia's national Pharmaceutical Benefits Scheme.

Third, NSW public and community-operated drug and alcohol services are not included in the data sets available for linkage. 
Finally, the study examines one Australian state rather than providing a truly national perspective. There are similarities in health system organisation between Australian states, but some findings may not generalise to other states. There is also some imprecision in population, service and outcome estimates due to interstate migration and cross-border service flows. Approximately $2.7 \%$ of the NSW population emigrates each year, and deaths of NSW residents occurring in other states are not recorded in the NSW Registry of Births, Deaths and Marriages. Therefore, mortality rates will be underestimated. Nationally linked data may become available in later stages of the project, subject to future approval.

\section{COLLABORATION}

Access to NSW unit record data is available to researchers with the specific approval of the NSW Population Health and Services Research Ethics Committee. Approval does not permit data sharing with other researchers. The MHLL investigators are interested in collaboration with other researchers or groups examining these issues at a health system level.

\section{Author affiliations}

${ }^{1}$ InforMH, System Information and Analytics Branch, NSW Ministry of Health, North Ryde, New South Wales, Australia

${ }^{2}$ Northern Clinical School, Sydney Medical School, Faculty of Medicine and Health, The University of Sydney, Sydney, New South Wales, Australia

${ }^{3}$ Cancer Institute NSW, Eveleigh, New South Wales, Australia

${ }^{4}$ School of Psychiatry, University of New South Wales, Sydney, New South Wales, Australia

${ }^{5}$ Epidemiological and Social Psychiatric Research institute, Erasmus Medical Centre, Erasmus University Rotterdam, Rotterdam, The Netherlands

${ }^{6}$ Parnassia Psychiatric Institute, Mental Health Group Europoort, Barendrecht, The Netherlands

${ }^{7}$ London Spinal Cord Injury Centre, Royal National Orthopaedic Hospital NHS Trust, Stanmore, UK

${ }^{8}$ Queensland Centre for Mental Health Research, University of Queensland, Brisbane, Queensland, Australia

Acknowledgements The authors would like to thank Dr Karin Lines, Executive Director, Mental Health Branch, for support and funding during the initiation of the project, and Benjamin Chow for research assistant support.

Contributors GS conceived the study. All the authors were involved in planning and study design. MA and GS manage and coordinate the study. JW and WC are responsible for data management and development. Data analysis is conducted by JW, WC and GS. GS, JW and MA drafted the manuscript. All the authors reviewed and revised the manuscript, and approved the submitted version of the paper.

Funding The MHLL programme is carried out by the InforMH unit, System Information and Analytics Branch, NSW Ministry of Health, within the standard operating budget of that unit. The Mental Health Branch, NSW Ministry of Health, has provided supplementary funds for 2018-2019 and 2019-2020 from NSW Mental Health Reform funding.

Competing interests None declared.

Patient consent for publication Not required.

Ethics approval Data linkage and waiver of consent have been approved by the NSW Population and Health Service Research Ethics Committee (AU RED Reference number: HREC/17/CIPHS/48 and Cancer Institute NSW Reference numbers: 2017/ HRE1105, 2018/UMB0301, 2018/UMB0302, 2018/UMB0303, 2018/UMB0304, 2019/UMB0208, 2019/UMB0301, 2019/UMB0302, 2019/UMB0606 and 2019/ UMB0607).

Provenance and peer review Not commissioned; externally peer reviewed.
Data availability statement № data are available.

Open access This is an open access article distributed in accordance with the Creative Commons Attribution Non Commercial (CC BY-NC 4.0) license, which permits others to distribute, remix, adapt, build upon this work non-commercially, and license their derivative works on different terms, provided the original work is properly cited, appropriate credit is given, any changes made indicated, and the use is non-commercial. See: http://creativecommons.org/licenses/by-nc/4.0/.

ORCID iD

Grant Sara http://orcid.org/0000-0002-3762-1711

\section{REFERENCES}

1 Firth J, Siddiqi N, Koyanagi A, et al. The Lancet psychiatry Commission: a blueprint for protecting physical health in people with mental illness. Lancet Psychiatry 2019;6:675-712.

2 Wahlbeck K, Westman J, Nordentoft M, et al. Outcomes of Nordic mental health systems: life expectancy of patients with mental disorders. Br J Psychiatry 2011;199:453-8.

3 Liu NH, Daumit GL, Dua T, et al. Excess mortality in persons with severe mental disorders: a multilevel intervention framework and priorities for clinical practice, policy and research agendas. World Psychiatry 2017;16:30-40.

4 Ajetunmobi O, Taylor M, Stockton D, et al. Early death in those previously hospitalised for mental healthcare in Scotland: a nationwide cohort study, 1986-2010. BMJ Open 2013;3:e002768.

5 Chesney E, Goodwin GM, Fazel S. Risks of all-cause and suicide mortality in mental disorders: a meta-review. World Psychiatry 2014;13:153-60.

6 Olfson M, Gerhard T, Huang C, et al. Premature mortality among adults with schizophrenia in the United States. JAMA Psychiatry 2015;72:1172-81.

7 Saha S, Chant D, McGrath J. A systematic review of mortality in schizophrenia: is the differential mortality gap worsening over time? Arch Gen Psychiatry 2007;64:1123-31.

8 Hoang U, Stewart R, Goldacre MJ. Mortality after hospital discharge for people with schizophrenia or bipolar disorder: retrospective study of linked English hospital episode statistics, 1999-2006. BMJ 2011;343.

9 Suetani S, Whiteford HA, McGrath JJ. An urgent call to address the deadly consequences of serious mental disorders. JAMA Psychiatry 2015;72:1166-7.

10 Department of Health. Fifth national mental health and suicide prevention plan. Canberra: Australian Government, 2017.

11 National Mental Health Commission. Equally well consensus statement: improving the physical health and wellbeing of people living with mental illness in Australia. Sydney: NMHC, 2016.

12 Hennekens $\mathrm{CH}$, Hennekens AR, Hollar D, et al. Schizophrenia and increased risks of cardiovascular disease. Am Heart $J$ 2005;150:1115-21.

13 Kisely S, Forsyth S, Lawrence D. Why do psychiatric patients have higher cancer mortality rates when cancer incidence is the same or lower? Aust N Z J Psychiatry 2016;50:254-63.

14 Irwin KE, Park ER, Shin JA, et al. Predictors of disruptions in breast cancer care for individuals with schizophrenia. Oncologist 2017;22:1374-82.

15 Chou FH-C, Tsai K-Y, Wu H-C, et al. Cancer in patients with schizophrenia: what is the next step? Psychiatry Clin Neurosci 2016;70:473-88.

16 Chang C-K, Hayes RD, Broadbent MTM, et al. A cohort study on mental disorders, stage of cancer at diagnosis and subsequent survival. BMJ Open 2014;4:e004295.

17 Mitchell AJ, Pereira IES, Yadegarfar M, et al. Breast cancer screening in women with mental illness: comparative meta-analysis of mammography uptake. Br J Psychiatry 2014;205:428-35.

18 Kisely S, Sadek J, MacKenzie A, et al. Excess cancer mortality in psychiatric patients. Can J Psychiatry 2008;53:753-61.

19 Kisely S, Crowe E, Lawrence D. Cancer-related mortality in people with mental illness. JAMA Psychiatry 2013;70:209-17.

20 Mai Q, Holman C D'Arcy J, Sanfilippo FM, et al. The impact of mental illness on potentially preventable hospitalisations: a populationbased cohort study. BMC Psychiatry 2011;11:163.

21 Cahoon EK, McGinty EE, Ford DE, et al. Schizophrenia and potentially preventable hospitalizations in the United States: a retrospective cross-sectional study. BMC Psychiatry 2013;13:37.

22 HealthStats NSW. Population by age. NSW Government, 2019. Available: http://www.healthstats.nsw.gov.au/Indicator/dem_pop_ age/dem_pop_age_trend [Accessed 29 Jul 2019]. 
23 Australian Bureau of Statistics. 2016 Census QuickStats. ABS, 2019. Available: https://quickstats.censusdata.abs.gov.au/census_services/ getproduct/census/2016/quickstat/1 [Accessed 29 Jul 2019].

24 Australian Bureau of Statistics. Migration, Australia (3412.0). Australian Bureau of Statistics, 2019. Available: https://www. abs.gov.au/AUSSTATS/abs@.nsf/DetailsPage/3412.02017-18? OpenDocument [Accessed 29 Sep 2019].

25 The Productivity Commission. Report on government services: mental health management. Australian Government, 2019. Available: https://www.pc.gov.au/research/ongoing/report-on-governmentservices/2018/health/mental-health-management [Accessed $29 \mathrm{Ju}$ 2019].

$26 \mathrm{CHeReL}$. Centre for Health Record Linkage. NSW health, 2019. Available: http://www.cherel.org.au/

27 Goldberg A, Borthwick A. The Choicemaker 2 record matching system. New York: Choicemaker Technologies, 2004.

28 CHeReL. Quality assurance. Centre for Health Record Linkage, 2019. Available: http://www.cherel.org.au/quality-assurance [Accessed 1 Oct 19].

$29 \mathrm{CHeReL}$. Data dictionaries. Centre for Health Record Linkage, 2019. Available: http://www.cherel.org.au/data-dictionaries [Accessed 29 Jul 2019].
30 National Centre for Classification in Health. The International statistical classification of diseases and related health problems, tenth revision, Australian modification. 7th edn. Sydney: National Centre for Classification in Health, Faculty of Health Sciences, The University of Sydney, 2010.

31 SNOMED International. SNOMED-CT, 2019. Available: www.snomed. org [Accessed 2 Aug 2019].

32 Australian Insitute of Health and Welfare. BreastScreen Australia monitoring report 2018. Canberra: Australian Government, 2018.

33 Australian Institute of Health and Welfare. Cervical screening in Australia 2019. Canberra: AlHW, 2019.

34 Cancer Institute NSW. Cervical cancer screening in New South Wales: annual statistical report 2012-2013. Sydney: Cancer Institute NSW, 2015.

35 NSW Register of Births Deaths and Marriages. NSW General Statistics. NSW Government. Available: https://www.bdm.nsw.gov. au/Pages/about-us/facts-statistics.aspx [Accessed 20 Sep 2019]

36 Sara G. Identifying suicide attempts in emergency department and admitted patient data. Sydney, Australia: Society for Mental Health Research, 2016. 